\title{
Protective Role of Black Tea Extract against Nonalcoholic Steatohepatitis-Induced Skeletal Dysfunction
}

\author{
Subhra Karmakar, ${ }^{1,2}$ Sangita Majumdar, ${ }^{2,3}$ Anasuya Maiti, ${ }^{2}$ Monalisa Choudhury,, 2 \\ Aniruddha Ghosh, ${ }^{2}$ Asankur S. Das, ${ }^{1,2}$ and Chandan Mitra ${ }^{1,2}$ \\ ${ }^{1}$ Pre-Clinical Physiology Laboratory, Tripura Institute of Paramedical Sciences, Hapania, Tripura 799014, India \\ ${ }^{2}$ Department of Physiology, Presidency College, Kolkata, Kolkata, India \\ ${ }^{3}$ Institute of Genetic Medicine and Genomic Science, Madhyamgram, Kolkata 700 128, India
}

Correspondence should be addressed to Chandan Mitra, physiol_presi@yahoo.co.in

Received 1 September 2010; Revised 20 March 2011; Accepted 20 March 2011

Academic Editor: Tomasz Miazgowski

Copyright (C) 2011 Subhra Karmakar et al. This is an open access article distributed under the Creative Commons Attribution License, which permits unrestricted use, distribution, and reproduction in any medium, provided the original work is properly cited.

\begin{abstract}
Aim. This paper aimed to examine the chemoprotective actions of aqueous black tea extract (BTE) against nonalcoholic steatohepatitis- (NASH-) induced skeletal changes in rats. Material. Wistar rats (body wt. 155-175 g) of both sexes, aged 4-5 months, were randomly assigned to 3 groups; Group A (control), Group B (60\% high-fat diet; HFD), and Group C (HFD + 2.5\% BTE). Methods. Several urinary (calcium, phosphate, creatinine, and calcium-to-creatinine ratio) serum (alkaline phosphatase and serum tartrate-resistant acid phosphatase), and molecular markers of bone turnover (receptor activator of NF- $\kappa \mathrm{B}$ ligand (RANKL), osteoprotegerin (OPG), and estrogen) were tested. Also, several bone parameters (bone density, bone tensile strength, bone mineral content, and bone histology) and calcium homeostasis were checked. Results. Results indicated that HFD-induced alterations in urinary, serum, and bone parameters as well as calcium homeostasis, all could be significantly ameliorated by BTE supplementation. Conclusion. Results suggest a potential role of BTE as a protective agent against NASH-induced changes in bone metabolism in rats.
\end{abstract}

\section{Introduction}

Nonalcoholic steatohepatitis (NASH) is a condition, which is described as accumulation of fat in liver with inflammation. This disorder may be observed in patients with no history of significant alcohol consumption, though histological examination may resemble alcohol-induced liver injury. It indeed may be the first clinical indication of insulin resistance, with complication of high blood pressure, coronary heart disease (CHD), and type 2 diabetes $[1,2]$. It is claimed that, after cancer, cirrhosis from NASH is now the second most common age-related cause of death in type II diabetes [3]. Similar alarming observation is the association between human bone diseases with liver diseases, like viral liver cirrhosis is a risk factor for increased loss of minerals from bone $[4,5]$. In an identical manner, patients with cholestatic liver disease have low bone turnover [6]. Even earlier [7, 8], it was reported that hepatic diseases are frequently associated with metabolic bone disorders. Hepatic osteodystrophy was reported to occur in up to $50 \%$ of patients with chronic liver disease (CLD). The results of this report suggested that increased bone resorption and less bone formation are the predominant cause of hepatic osteodystrophy in patients with CLD [9]. Osteopenia and osteoporosis are common complications of chronic liver disease. Patients with chronic liver disease may have other complications, such as malnutrition, loss of muscle mass, hypogonadism, low calcium intake, and vitamin D deficiency, all of which alter normal bone metabolism [10]. Several earlier studies had indicated the possible role of lipids in osteoporosis. High lipid levels were found closely related with decrease in bone mineral density (BMD) coupled with osteoporosis [1113] as well as other disorders that may be a consequence of high lipids, including cardiovascular calcification [1416] and atherosclerosis [11]. Consistent with these findings are the results of two in vivo studies that have shown 
that mice [17] and chickens [18] fed on a high-fat, highcholesterol diet have reduced bone mineral density. An earlier study also had indicated that diets with high saturated fat content can produce deleterious effects on the absorption of dietary calcium and consequently an adverse effect on bone mineralization in growing animals [19]. Perhaps even more significant are data reporting that the loss in bone mineral density by high lipid diet can be revived with antioxidants, suggesting a possible mechanism of action through suppression of lipid oxidation levels [18].

Tea (Camellia sinensis) is rich in polyphenolic compounds, collectively known as the tea flavonoids. Its therapeutic value come forefront with numerous reports on tea as antioxidants, hypolipidemic, antineoplastic, and hypocholesterolemic [20-23]. Tea also has been reported to possess a cardiovascular-protective effect $[24,25]$. In an epidemiological report it has been suggested that skeletal health is better preserved in aged women who drank tea than nontea drinkers [26]. Similar epidemiological studies have confirmed that tea drinking may be a possible preventive measure to reduce risk of bone loss in postmenopausal women as well as in men by increasing BMD [27, 28]. Estrogenic activity of naturally occurring isoflavones by virtue of their ability to bind nuclear estrogen receptor was reported earlier [29], and, recently, soy isoflavones with weak estrogen-like activities have been reported to modulate bone metabolism and serum lipids in perimenopausal women [30]. A recent study has further indicated that soy isoflavone can reduce the risk of obesity and preserve bone health in menopausal women [31]. Moderate consumption of tea, which contains flavonoids closely related to soy isoflavones, has been reported to be associated with higher BMD in men and women $[26,27]$ and lower rates of fracture [32, 33]. Results of series of studies from our laboratory with aqueous black tea extract [34-36] further support the idea that phytocompounds have efficacy in preventing bone loss. This study aimed to examine the protective role of black tea extract (BTE) against nonalcoholic steatohepatitis- (NASH-) induced skeletal dysfunction.

\section{Methods}

2.1. Animals. As NASH does not have any gender specificity and is seen in both sexes, animals from both sexes were selected for this study. Wistar rats, both male and female, aged 4-5 months, weighing 155-170 g were procured from a local authorized breeder registered under the Committee for the Purpose of Control and Supervision of Experiments on Animals (CPCSEA), Ministry of Environment and Forests, Government of India. Upon arrival at our institute, all animals were kept under standard conditions (12 hours light/dark schedule and at $25 \pm 2^{\circ} \mathrm{C}$ room temperature throughout the experimental period) for a week with free access to drinking water and standard laboratory diet composed of $71 \%$ carbohydrate, $18 \%$ protein, $7 \%$ fat, and $4 \%$ salt mixture [37]. All animal experiments were performed according to the ethical guidelines suggested by the Institutional Animal Ethics Committee (IAEC) and Committee for the Purpose of Control and Supervision of Experiments on Animals (CPCSEA), Ministry of Environment and Forests, Government of India.

2.2. Diet and Treatment. Eighteen animals were randomly assigned to three groups: Group A (regular diet), Group B (high-fat diet), and Group C (high-fat diet + BTE). Each group contained six animals, three male and three female. Group A animals were fed standard laboratory diet [37] containing $71 \%$ carbohydrate, $18 \%$ protein, $7 \%$ fat, and $4 \%$ salt mixture. Group B animals were fed high-fat diet [38] containing carbohydrate: $22 \%$, fat: $60 \%$ containing corn oil (palmitic acid: $6.3-18.2 \%$, stearic acid: $0.9-4.5 \%$, oleic acid: 18.5-46.1\%, linoleic acid: 36.6-66.8\%, linolenic acid: 0 $2 \%$, and arachidonic acid: $0-1.4 \%$ ) [39], and protein: $18 \%$. Animals of group $\mathrm{C}$, in addition to high fat diet, were fed $2.5 \%(25 \mathrm{~g} / \mathrm{L})$ BTE by gavage technique for 30 days at a single dose of $10 \mathrm{~mL} / \mathrm{kg} /$ day [40]. Animals of group A and B were given deionized water by gavage technique, $10 \mathrm{~mL} / \mathrm{kg} /$ day as vehicle. In our preliminary studies, a fourth group (Group D) of animals was included containing six animals (male 3 , female 3), which were given standard laboratory diet simultaneously with $2.5 \%$ BTE by gavage technique for 30 days at a single dose of $10 \mathrm{~mL} / \mathrm{kg} /$ day. As aqueous black tea extract in Group D animals independently could not produce any significant variation of results in marker parameters of $\mathrm{NASH}$, compared to control, this group was not considered for further detailed study to restrict animal use as per recommendation of the Animal Ethics Committee.

2.3. Preparation of Aqueous BTE. The black tea (Camellia sinensis) extract was prepared from CTC (Curl, Tear and Crush) BOP- (Broken Orange Pickoe-) grade black clonal tea. It was processed and supplied by Tocklai Experimental Station, Jorhat, Assam, India to the Drug Development Division, Indian Institute of Chemical Biology, Jadavpur, Kolkata, India. We received a generous gift from that institute. A fresh $2.5 \%$ aqueous BTE was prepared everyday following the method of Wei et al. [40]. Twenty-five gram of black tea was added to $500 \mathrm{~mL}$ of boiling water and was steeped for $15 \mathrm{~min}$. The infusion was cooled to room temperature and then filtered. The tea leaves were extracted a second time with $500 \mathrm{~mL}$ of boiling water and filtered, and the two filtrates were combined to obtain a $2.5 \%$ aqueous black tea extract ( $2.5 \mathrm{~g}$ of tea leaf $/ 100 \mathrm{~mL}$ water). The resulting clear solution is similar to tea brews consumed by humans.

\subsection{Selection of Effective Dose of High Fat Diet and Black Tea Extract. For determination of effective dose (ED) of high fat diet (HFD) and black tea extract (BTE), dose response studies were undertaken. In case of high fat, it was observed that although significant changes could be seen from $30 \%$ of high fat onward, but both biochemical and histological changes were most prominent with 60\% HFD. Similar changes with $60 \%$ HFD were reported earlier [38]. As for BTE, a submaximal dose response study revealed that significant recovery responses were seen with doses between}


2-3\% (w/v) aqueous BTE. Recovery responses with similar dose of BTE were also reported earlier [40].

2.5. Urine Collection. Fasting urine was collected for 24 hours (9 AM to next day $9 \mathrm{AM}$ ) according to the standard laboratory procedure [41] as described elsewhere by Chanda et al. [37]. Care was taken so that no urine was lost through evaporation. Total volume of urine was measured, and the following parameters were assessed.

\subsection{Estimation of Urinary Parameters}

2.6.1. Urinary Calcium. Urinary calcium was measured according to the method of Adeniyi et al. [42]. The assay of calcium was based on the principle that metal complexing dye orthocresopthalein complexone (CPC) forms a chromophore with calcium in alkaline solution. Diethylamine (DEA) were added to enhance the colour intensity. For urinary calcium estimation, to $20 \mu \mathrm{L}$ of urine $1 \mathrm{~mL}$ $\mathrm{CPC}$ reagent and $1 \mathrm{~mL}$ DEA buffer was added. Colour intensity was measured at $575 \mathrm{~nm}$ against a blank by using a UV-double beam spectrophotometer (Shimadzu 160 A; Shimadzu Corporation, Kyoto, Japan). Calcium carbonate $\left(\mathrm{CaCO}_{3}\right)$ solution $\mathrm{pH}-3.0$ was used as standard. All the reagents were prepared with calcium-free triple distilled water.

2.6.2. Urinary Phosphate. Urinary phosphate was measured according to the method of Lowry and Lopez [43]. For urinary phosphate estimation, $10 \mu \mathrm{L}$ of urine was diluted 50 times with distilled water and to it $1 \mathrm{~mL}$ molybdate reagent and $200 \mu \mathrm{L}$ amino naphthol sulfonic acid (ANSA) was added, mixed well, and kept in dark for 10 minutes. Reading was taken at $630 \mathrm{~nm}$ against blank. The concentration of phosphate in urine was calculated using a standard curve of monopotassium phosphate $\left(\mathrm{KH}_{2} \mathrm{PO}_{4}\right)$.

2.6.3. Urinary Creatinine. Urinary creatinine was measured according to the method of R. L. Nath and R. K. Nath [44]. For urinary creatinine estimation, $50 \mu \mathrm{L}$ of urine was diluted 10 times and to it $2 \mathrm{~mL}$ saturated picric acid and $150 \mu \mathrm{L} 10 \%$ sodium hydroxide solution were added, mixed and kept for 15 minutes at $37^{\circ} \mathrm{C}$ incubator. To it, $5 \mathrm{~mL}$ of water was added. Reading was taken at $520 \mathrm{~nm}$ against blank. The concentration of creatinine in urine was calculated using a standard curve of creatinine.

2.7. Serum Collection. Blood was collected directly from the heart under urethane anesthesia $(1.7 \mathrm{mg} / \mathrm{g}$ body weight). Serum was obtained by using standard laboratory protocol.

2.8. Estimation of Serum Alkaline Phosphatase (AP) Activity. Serum alkaline phosphatase was measured using $\mathrm{p}$ nitrophenyl phosphate as substrate [45]. Alkaline phosphatase activity was measured by the hydrolysis of $\mathrm{p}$ NPP (paranitrophenyl phosphate) at $\mathrm{pH}-10.8$ using glycine$\mathrm{NaOH}$ buffer at $37^{\circ} \mathrm{C}$. In brief, $0.5 \mathrm{~mL}$ of $5.5 \mathrm{mM}$ p-NPP in $0.4 \mathrm{~mL}$ of glycine- $\mathrm{NaOH}$ buffer $(\mathrm{pH}-10.8)$ solution were pipetted in a test tube and incubated at $37^{\circ} \mathrm{C}$ for 10 minutes. After incubation, $0.05 \mathrm{~mL}$ of sample was added, mixed, and incubated at $37^{\circ} \mathrm{C}$ for 30 minutes. Reaction was stopped by adding $4 \mathrm{~mL}$ of $0.1 \mathrm{~N} \mathrm{NaOH}$, and reading was taken at $410 \mathrm{~nm}$ against a blank in a spectrophotometer (Shimadzu 160 A; Shimadzu Corporation, Kyoto, Japan).

\subsection{Estimation of Serum Tartrate-Resistant Acid Phosphatase} (TRAP) Activity. Serum TRAP activity was estimated by kinetic method by using reagent kit (LABKIT, Spain). Briefly, unhemolyzed serum was mixed with the test reagent $(10 \mathrm{mM}$ $\alpha$-naphthyl phosphate, $6 \mathrm{mM}$ Fast Red TR, and $2 \mathrm{mM}$ sodium tartrate in $50 \mathrm{mM}$ sodium citrate buffer, $\mathrm{pH}-5.2$ ) and the absorbance of the sample was read at $405 \mathrm{~nm}$ at 1 minute interval thereafter for 3 minutes. The difference of absorbance and the average absorbance difference per minute $(\Delta \mathrm{A} / \mathrm{min})$ was calculated [46].

2.10. Estimation of Serum Estradiol. Serum was obtained by using standard laboratory protocol. Serum estrogen level $(\mathrm{pg} / \mathrm{mL})$ was determined by using the ELISA EIAgen Estradiol kit (Adaltis Italia, Italy). All samples were assayed in duplicate. The intra-assay coefficient of variation was $9.08 \%$. To avoid inter-assay variation all samples were run at one time.

2.11. Estimation of Serum RANKL. Serum RANKL was estimated by using the ELISA kits (Quantikine, R \& D Systems Inc., Minneapolis, MN, USA). All samples were assayed in duplicate. The intra-assay variation was $11.75 \%$. All samples were run at one time to avoid inter-assay variation. Optical density of each well was determined by using a microplate reader (Thermo Labsystems, Finland).

2.12. Estimation of Serum Osteoprotegerin (OPG). Serum OPG was estimated by using the ELISA kits (Quantikine, R \& D Systems Inc., Minneapolis, MN, USA). All samples were assayed in duplicate. The intra-assay variation was $10.09 \%$. All samples were run at one time to avoid interassay variation. Optical density of each well was determined by using a microplate reader (Thermo Labsystems, Finland).

2.13. Measurement of Bone Density. The right femur, eighth thoracic rib, eighth thoracic vertebra, and fourth lumbar vertebra were freed off soft tissue and cleaned using small scissors, tweezers, and cotton gauze. Before measurement of the density, femur was cut at the middiaphysis and the marrow was washed out. Bone density was measured according to the method described by Arjmandi et al. [47] by using Archimedes' principle. Briefly, each bone was put in an unstoppered vial filled with deionized water, and the vial was placed under a vacuum for 90 minutes to ensure that all the trapped air diffused out of the bone. Each bone was removed from the vial, blotted with gauze sponge, weighed, and returned to the vial containing deionized water. The bone was reweighed in water and density was calculated ( $\mathrm{g} / \mathrm{cm}^{3}$ bone volume). 
2.14. Estimation of Bone Tensile Strength. After sacrifice of the animal, left femur was excised and cleaned off adhering soft tissues. Bone tensile strength was measured as described by Shapiro and Heaney [48] using a hand-held force meter (Excel Enterprises, India). Briefly, the femur was supported latitudinally on each end, and pressure was placed directly onto the middle of the bone until it fractured. The breaking force $(\mathrm{kg})$ was recorded.

2.15. Estimation of Bone Calcium and Bone Phosphate Level. Right femur, eighth thoracic rib, eighth thoracic vertebra, and fourth lumbar vertebra were removed and cleaned of adhering tissue. The whole bone was extracted two times with a 1:1 mixture of ethanol and diethyl ether for 48 hours and one time with diethyl ether for 24 hours. The dehydrated and defatted bones were turned into ash at $600 \circ \mathrm{C}$ for 48 hours and hydrolyzed in $6 \mathrm{~N} \mathrm{HCl}$ for determination of calcium and phosphate [49]. Calcium and phosphate were estimated according to the method as described, respectively, by Adeniyi et al. [42] and Lowry and Lopez [43].

2.16. Preparation of Intestinal Loops. After the experimental period was over, the animals of all groups were fasted for 16 hours. The preparation of animals and intestinal loops for the study of calcium transference in situ was made by following the method as described elsewhere by Islam et al. [50]. Briefly, the animal was anesthetized (urethane, $1.7 \mathrm{mg} / \mathrm{kg}$ body weight), the abdomen of each animal was opened through a midline longitudinal incision, the bile duct was ligated and duodenal, jejunal, and ileal segments were located. Two ligatures, one proximal and the other distal, were applied tightly in each loop measuring about $8 \mathrm{~cm}$ in all duodenal, jejunal, and ileal segments. Loops were so selected that each contained 8-10 vessels, and care was taken so that no major blood vessels were occluded by the ligature.

2.17. Measurement of Intestinal Calcium Transference. For the measurement of intestinal calcium transference, $1 \mathrm{~mL}$ of prewarmed $\left(37^{\circ} \mathrm{C}\right)$ Tris- $\mathrm{HCl}$ buffer solution containing $0.2 \mathrm{mM} \mathrm{CaCl}_{2}$ was injected with a 25 -gauge needle in each ligated segment. The intestinal loops were placed in their usual position and the abdomen was closed. After one hour, animals were sacrificed, the preselected loops were removed and the fluid from each loop was collected separately, together with a few washings of the lumen with triple distilled water. The collected fluid was then increased to a definite volume with calcium free triple distilled water. A fraction of this fluid was then used for the estimation of $\mathrm{Ca}^{2+}$ using a double beam spectrophotometer (Shimadzu, UV$160 \mathrm{~A}$ ) according to the method described by Adeniyi et al. [42]. The difference between the amount of $\mathrm{Ca}^{2+}$ introduced and the amount left unabsorbed was used to estimate the amount of $\mathrm{Ca}^{2+}$ absorbed. The intestinal part constituting the loop was dried on a watch glass in an electric oven at $90^{\circ} \mathrm{C}$ to attain a constant weight, which was recorded as the weight of the dried loop. Intestinal transference of calcium was expressed as $\mu \mathrm{M}$ of calcium/g of dry weight/hour.
2.18. Preparation of Intestinal Mucosal Extract. After sacrificing the animal and opening of the abdomen, the whole of the small intestine was quickly removed. The portion comprised of the duodenum, jejunum, and ileum were separated and chilled in ice. Intestinal mucosa was collected as described by Maenz and Cheeseman [51], and the scrapings were homogenized according to the method of Koyama et al. [52] .

2.19. Estimation of Intestinal Mucosal Alkaline Phosphatase Activity. The activity of alkaline phosphatase of intestinal mucosa was estimated by using p-nitrophenyl phosphate as substrate [45]. The protein content of the homogenate used for the study was determined using the method of Lowry et al. [53].

\subsection{Estimation of Intestinal Mucosal $\mathrm{Ca}^{2+}$ Activated ATPase} Activity. The activity of the enzyme $\mathrm{Ca}^{2+}$-ATPase was also studied from the mucosal extract using the method of Rorive and Kleinzellar [54]. The assay was based on the principle that the release of inorganic phosphate $(\mathrm{Pi})$ from ATP is measured in presence of either $\mathrm{Ca}^{2+}$ or $\mathrm{Mg}^{2+}$. For the assay of mucosal $\mathrm{Ca}^{2+}$, activated ATPase, $250 \mu \mathrm{L} 0.4 \mathrm{M}$ Tris- $\mathrm{HCl}$ buffer pH-7.4 and $250 \mu \mathrm{L} 40 \mathrm{mM}$ ATP (Tris-salt, Sigma) were added into three of the test tubes placed on ice. To tubes 1 and $3,250 \mu \mathrm{L}$ of $40 \mathrm{mM} \mathrm{CaCl} 2$ were added. At time zero, the reaction was started by addition of $250 \mu \mathrm{L}$ of mucosal homogenate to tubes 1 and 2 . The volumes in all tubes were adjusted to $2 \mathrm{~mL}$ with calcium free distilled water. The three tubes were then incubated at $37^{\circ} \mathrm{C}$ with gentle shaking for 30 minutes. Under this condition the release of Pi is linear unto 60 mins. The reaction was stopped by transfer of the tubes to ice and addition of $0.4 \mathrm{~mL}$ ice-cold $35 \%(\mathrm{w} / \mathrm{v})$ trichloro acetic acid (TCA). The tubes were then centrifuged for 10 minutes at $10,000 \mathrm{rpm}$ in a refrigerated centrifuge. The protein pellet was dissolved in $1 \mathrm{~mL}$ of $1 \mathrm{~N}$ sodium hydroxide $(\mathrm{NaOH})$, and protein content was determined following the method of Lowry et al. [53]. Phosphate liberated during $\mathrm{Ca}^{2+}$ ATPase enzyme activity was estimated by the method of Lowry and Lopez [43].

2.21. Bone Tissue Collection and Processing. The left proximal tibia and fourth lumbar vertebra were removed, dissected free of soft tissue, and fixed with 4\% paraformaldehyde for 16-18 hours at $4^{\circ} \mathrm{C}$. After fixation, specimens were washed for 12 hours at $5^{\circ} \mathrm{C}$ in each of the following series of solutions: $0.01 \mathrm{M}$ PBS containing 5\% glycerol, $0.01 \mathrm{M}$ PBS containing 10\% glycerol, and $0.01 \mathrm{M}$ PBS containing $15 \%$ glycerol. The specimens were then decalcified in EDTA-G solution (14.5 g EDTA, $1.25 \mathrm{~g} \mathrm{NaOH}$, and $15 \mathrm{~mL}$ glycerol, pH-7.3) for 10-14 days. The decalcified tissues were washed sequentially at $5^{\circ} \mathrm{C}$ for 12 hours in (a) $15 \%$ sucrose and $15 \%$ glycerol in PBS, (b) $20 \%$ sucrose and $10 \%$ glycerol in PBS, (c) $20 \%$ sucrose and $5 \%$ glycerol in PBS, (d) $20 \%$ sucrose in PBS; $10 \%$ sucrose in PBS, (e) 5\% sucrose in PBS, and (f) $100 \%$ PBS. Then the tissues were washed with PBS and dehydrated in graded series of alcohols, followed by clearing in xylene, and finally embedded in paraffin [55]. The specimen were cut into 5-6 $\mu \mathrm{m}$ sections and stained with 
haematoxylin-eosin. Representative sections were observed and photomicrography was performed with the help of a bright field microscope equipped with a digital camera (Carl Zeiss, Germany).

2.22. Statistical Analysis. Data were expressed as mean \pm S.E.M. obtained from a particular group comprising both male and female animals. Data were compared using Kruskal-Wallis nonparametric ANOVA followed by MannWhitney "U" multiple comparison test (software version 2.6.5, StatsDirect, UK). Differences were considered significant if $P<.05$.

\section{Results}

3.1. Urinary Calcium, Phosphate, and Creatinine Excretion Profiles and Calcium-to-Creatinine Ratio. The urinary calcium, phosphate, and creatinine excretion profiles together with $\mathrm{Ca}$ : Cr ratio of control group (Group A), HFD (Group B), and HFD + BTE (Group C) are shown in Table 1 . Compared to control group, animals of HFD-fed group showed a significant increase in all the urinary parameters studied, namely, calcium, phosphate, creatinine, and $\mathrm{Ca}: \mathrm{Cr}$ ratio $(P<.01)$. Elevated response of all these parameters was significantly counter regulated in the HFD + BTEsupplemented group of rats (Group C).

3.2. Serum Alkaline Phosphatase (AP) and Tartrate-Resistant Acid Phosphatase (TRAP) Activity Profiles. The serum alkaline phosphatase (AP) activity profile of rats of control, HFD, and HFD + BTE supplemented groups are shown in Table 2. Rats of HFD-fed group (Group B) showed a significant increase in serum alkaline phosphatase activity when compared to animals of control group $(P<.01)$ (Group A). This increase in AP activity was significantly lowered $(P<.01)$ in rats receiving BTE (Group C). Likewise, the significant increase $(P<.01)$ in TRAP activity in HFDfed group (Group B), compared to control (Group A), could be effectively reduced by aqueous BTE supplementation (Group C; Table 2).

3.3. Bone Density Profiles. Animals in the HFD-fed group (Group B) had significantly lower densities of the right femur $(P<.01)$, eighth thoracic rib $(P<.01)$, eighth thoracic vertebra $(P<.01)$, and fourth lumbar vertebra $(P<.01)$, compared with the control group (Group A). BTE supplementation could produce significant increase $(P<$ $.01)$ in bone density of all bones: right femur $(P<.01)$, eighth thoracic rib $(P<.01)$, eighth thoracic vertebra $(P<$ $.05)$, and fourth lumbar vertebra $(P<.01$; Table 3$)$.

3.4. Bone Tensile Strength. Figure 1 shows that compared to control, bone tensile strength in HFD-fed animals was significantly reduced $(P<.01)$. BTE supplementation in these animals was found effective in recovering $(P<.01)$ this tensile strength back to control group level.

3.5. Bone Calcium and Bone Phosphate Levels. Results of bone calcium and phosphate levels are shown in Table 4 .

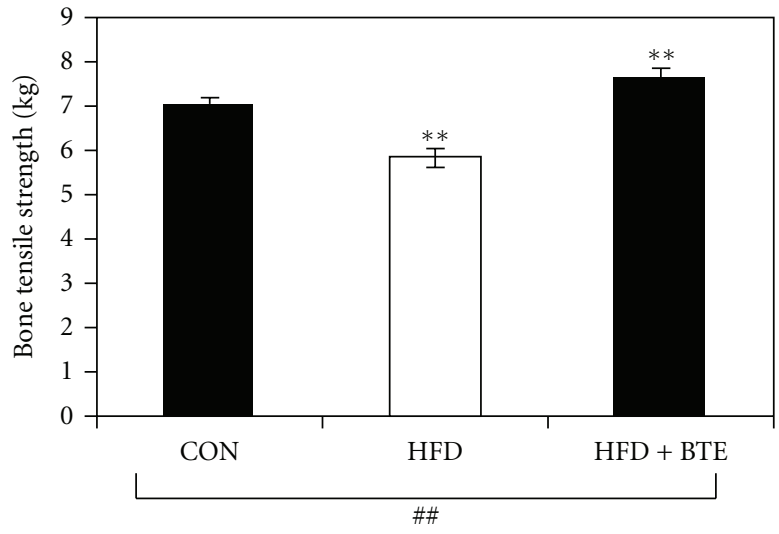

FIGURE 1: Graphical presentation of bone tensile strength of control (CON; Group A), HFD (Group B), and HFD + BTE supplemented (Group C) groups of animals. Values are expressed as mean \pm

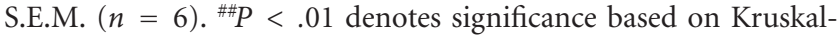
Wallis non-parametric ANOVA test, ${ }^{* * P}<.01$ denotes significance based on Mann-Whitney "U" multiple comparison test.

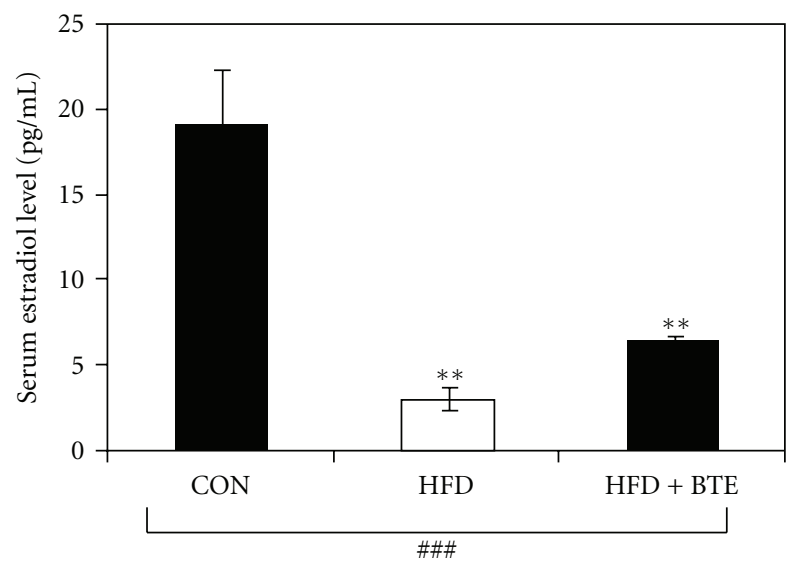

Figure 2: Serum estradiol level of control (CON; Group A), HFD treated (Group B), and HFD + BTE (Group C) supplemented female groups of rats. Values are expressed as mean \pm S.E.M. ( $n=6$, female data only). ${ }^{\# \# P} P<.001$ denotes significance level based on Kruskal-Wallis nonparametric ANOVA test and ${ }^{* *} P<.01$ denotes significance level based on Mann-Whitney " $U$ " multiple comparison test.

Animals of HFD-fed group (Group B), compared to control group (Group A), showed a marked decrease in calcium and phosphate levels of right femur (calcium: $P<.01$; phosphate: $P<.01$ ), eighth thoracic rib (calcium: $P<.01$; phosphate: $P<.01$ ), eighth thoracic vertebra (calcium: $P<.01$; phosphate: $P<.01$ ), and fourth lumbar vertebra (calcium: $P<.01$; phosphate: $P<.01)$. When these HFD-fed animals were supplemented with BTE (Group C), significant recovery in content of both minerals was seen.

3.6. Serum Estradiol Level. Figure 2 shows the effects of supplementation of BTE on serum estradiol level of HFD, fed rats. Compared to control (Group A), a significant decrease in estradiol level was seen in HFD-fed (Group B) animals 
TABLE 1: Urinary excretion of calcium, phosphate, creatinine, and calcium : creatinine (Ca: Cr) ratio in control (Group A), HFD (Group B) and HFD + BTE (Group C) supplemented groups of rats.

\begin{tabular}{|c|c|c|c|c|c|c|}
\hline \multirow{2}{*}{ Parameters } & \multirow{2}{*}{$\begin{array}{c}\text { Control } \\
\text { (Group A) }\end{array}$} & \multirow{2}{*}{$\begin{array}{l}\text { High-fat } \\
\text { (Group B) }\end{array}$} & \multirow{2}{*}{$\begin{array}{c}\text { High-fat + BTE } \\
(\text { Group C) }\end{array}$} & \multirow{2}{*}{ Significance level ${ }^{\# \#}$} & \multicolumn{2}{|c|}{ Significance level* } \\
\hline & & & & & Gr. A versus Gr. B & Gr. B versus Gr. C \\
\hline Urinary calcium (mg/24 h) & $0.81 \pm 0.24$ & $3.21 \pm 0.56$ & $1.01 \pm 0.11$ & $P<.01$ & $P<.01$ & $P<.01$ \\
\hline Urinary phosphate $(\mathrm{mg} / 24 \mathrm{~h})$ & $1.13 \pm 0.084$ & $3.21 \pm 0.085$ & $1.32 \pm 0.206$ & $P<.01$ & $P<.01$ & $P<.01$ \\
\hline Urinary creatinine $(\mathrm{mg} / 24 \mathrm{~h})$ & $0.45 \pm 0.16$ & $0.97 \pm 0.021$ & $0.65 \pm 0.09$ & $P<.01$ & $P<.01$ & $P<.01$ \\
\hline $\mathrm{Ca}: \mathrm{Cr}$ & $1.132 \pm 0.16$ & $3.37 \pm 0.54$ & $1.48 \pm 0.14$ & $P<.01$ & $P<.01$ & $P<.01$ \\
\hline
\end{tabular}

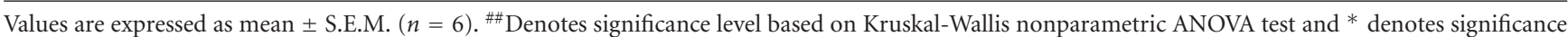
level based on Mann-Whitney "U" multiple comparison test.

TABLE 2: Serum alkaline phosphatase (AP) activity and serum tartrate-resistant acid phosphatase (TRAP) activity in control (Group A), HFD (Group B) and HFD + BTE (Group C) supplemented groups of rats.

\begin{tabular}{|c|c|c|c|c|c|c|}
\hline \multirow{2}{*}{ Serum enzyme activity } & \multirow{2}{*}{$\begin{array}{c}\text { Control } \\
\text { (Group A) }\end{array}$} & \multirow{2}{*}{$\begin{array}{l}\text { High-fat } \\
\text { (Group B) }\end{array}$} & \multirow{2}{*}{$\begin{array}{l}\text { High-fat + BTE } \\
\quad(\text { Group C) }\end{array}$} & \multirow{2}{*}{ Significance level ${ }^{\#}$} & \multicolumn{2}{|c|}{ Significance level* } \\
\hline & & & & & Gr. A versus Gr. B & Gr. B versus Gr. C \\
\hline Alkaline phosphatase (U/L) & $9.41 \pm 0.22$ & $16.48 \pm 3.2$ & $9.97 \pm 0.24$ & $P<.01$ & $P<.01$ & $P<.01$ \\
\hline TRAP (U/L) & $2.1 \pm 0.32$ & $4.29 \pm 0.26$ & $2.04 \pm 0.28$ & $P<.01$ & $P<.01$ & $P<.01$ \\
\hline
\end{tabular}

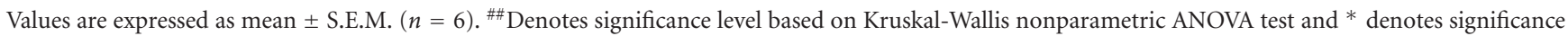
level based on Mann-Whitney "U" multiple comparison test.

TABLE 3: Density of femur, eighth thoracic rib, eighth thoracic vertebra, and fourth lumbar vertebra in control group (Group A), HFD group (Group B), and HFD + BTE supplemented group (Group C) of rats.

\begin{tabular}{|c|c|c|c|c|c|c|}
\hline \multirow{2}{*}{ Parameters } & \multirow{2}{*}{$\begin{array}{c}\text { Control } \\
\text { (Group A) }\end{array}$} & \multirow{2}{*}{$\begin{array}{l}\text { High-fat } \\
\text { (Group B) }\end{array}$} & \multirow{2}{*}{$\begin{array}{c}\text { High-fat + BTE } \\
(\text { Group C) }\end{array}$} & \multirow{2}{*}{ Significance level ${ }^{\# \#}$} & \multicolumn{2}{|c|}{ Significance level* } \\
\hline & & & & & Gr. A versus Gr. B & Gr. B versus Gr. C \\
\hline \multicolumn{7}{|l|}{ Bone density $\left(\mathrm{gm} / \mathrm{cm}^{3}\right)$} \\
\hline Right femur & $1.39 \pm 0.02$ & $1.22 \pm 0.01$ & $1.34 \pm 0.007$ & $P<.01$ & $P<.01$ & $P<.01$ \\
\hline Eighth Thoracic Rib & $2.57 \pm 0.28$ & $1.44 \pm 0.03$ & $2.15 \pm 0.11$ & $P<.01$ & $P<.01$ & $P<.01$ \\
\hline Eighth Thoracic Vertebra & $1.33 \pm 0.03$ & $1.23 \pm 0.02$ & $1.299 \pm 0.01$ & $P<.05$ & $P<.05$ & $P<.01$ \\
\hline Fourth Lumbar Vertebra & $1.272 \pm 0.28$ & $1.44 \pm 0.03$ & $2.15 \pm 0.11$ & $P<.01$ & $P<.01$ & $P<.01$ \\
\hline
\end{tabular}

Values are expressed as mean \pm S.E.M. $(n=6) .{ }^{\# \#}$ Denotes significance level based on Kruskal-Wallis nonparametric ANOVA test and $*$ denotes significance level based on Mann-Whitney "U" multiple comparison test.

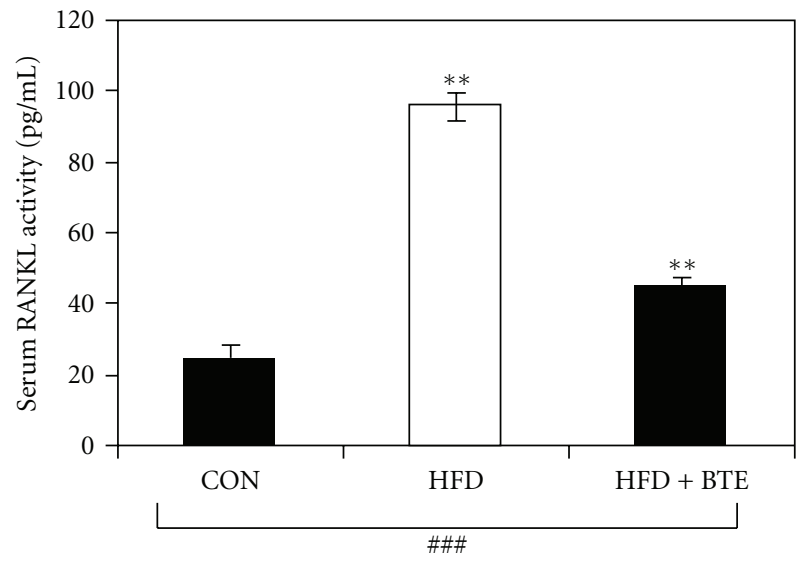

(a)

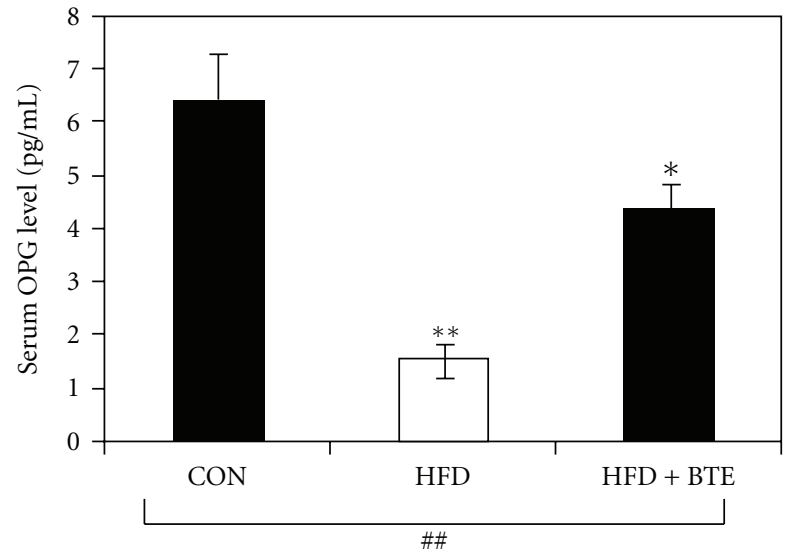

(b)

FIgURE 3: (a) Serum RANKL activity and (b) OPG level of control (CON; Group A), HFD treated (Group B), and HFD + BTE supplemented (Group C) groups of rats. Values are expressed as mean \pm S.E.M. $(n=6) .{ }^{\# \# P}<.001$ denotes significance level based on Kruskal-Wallis

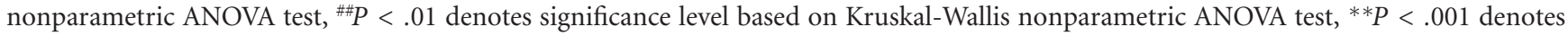
significance level based on Mann-Whitney " $U$ " multiple comparison test, and ${ }^{*} P<.05$ denotes significance level based on Mann-Whitney "U" multiple comparison test. 
TABLE 4: Bone mineral content of femur, eighth thoracic rib, eighth thoracic vertebra and fourth lumbar vertebra in control group (Group A), HFD group (Group B), and HFD + BTE supplemented groups (Group C) of rats.

\begin{tabular}{|c|c|c|c|c|c|c|}
\hline \multirow{2}{*}{ Parameters } & \multirow{2}{*}{$\begin{array}{c}\text { Control } \\
\text { (Group A) }\end{array}$} & \multirow{2}{*}{$\begin{array}{l}\text { High-fat } \\
\text { (Group B) }\end{array}$} & \multirow{2}{*}{$\begin{array}{c}\text { High-fat + BTE } \\
\text { (Group C) }\end{array}$} & \multirow{2}{*}{ Significance level } & \multicolumn{2}{|c|}{ Significance level* } \\
\hline & & & & & Gr. A versus Gr. B & Gr. B versus Gr. C \\
\hline \multicolumn{7}{|c|}{ Bone calcium (\% of ash weight) } \\
\hline Femur & $19.39 \pm 1.09$ & $9.73 \pm 0.53$ & $13.75 \pm 0.64$ & $P<.001$ & $P<.01$ & $P<.01$ \\
\hline Eighth thoracic rib & $23.39 \pm 0.84$ & $15.49 \pm 0.92$ & $23.01 \pm 1.38$ & $P<.01$ & $P<.01$ & $P<.01$ \\
\hline Eighth thoracic vertebra & $24.3 \pm 1.39$ & $13.7 \pm 0.7$ & $21.52 \pm 1.02$ & $P<.01$ & $P<.01$ & $P<.01$ \\
\hline Fourth lumbar vertebra & $25.68 \pm 0.57$ & $13.65 \pm 0.78$ & $18.56 \pm 0.8$ & $P<.001$ & $P<.01$ & $P<.01$ \\
\hline \multicolumn{7}{|c|}{ Bone phosphate (\% of ash Weight) } \\
\hline Femur & $8.6 \pm 0.49$ & $3.88 \pm 0.46$ & $7.81 \pm 0.62$ & $P<.01$ & $P<.01$ & $P<.01$ \\
\hline Eighth thoracic rib & $11.89 \pm 0.11$ & $6.24 \pm 0.45$ & $11.67 \pm 0.16$ & $P<.01$ & $P<.01$ & $P<.01$ \\
\hline Eighth thoracic vertebra & $10.67 \pm 0.36$ & $7.21 \pm 0.23$ & $10.72 \pm 0.43$ & $P<.01$ & $P<.01$ & $P<.01$ \\
\hline Fourth lumbar vertebra & $11.38 \pm 0.39$ & $5.34 \pm 0.28$ & $11.56 \pm 0.12$ & $P<.01$ & $P<.01$ & $P<.01$ \\
\hline
\end{tabular}

Values are expressed as mean \pm S.E.M $(n=6) .{ }^{\#}$ denotes significance level based on Kruskal-Wallis nonparametric ANOVA test and $*$ denotes significance level based on Mann-Whitney "U" multiple comparison test.

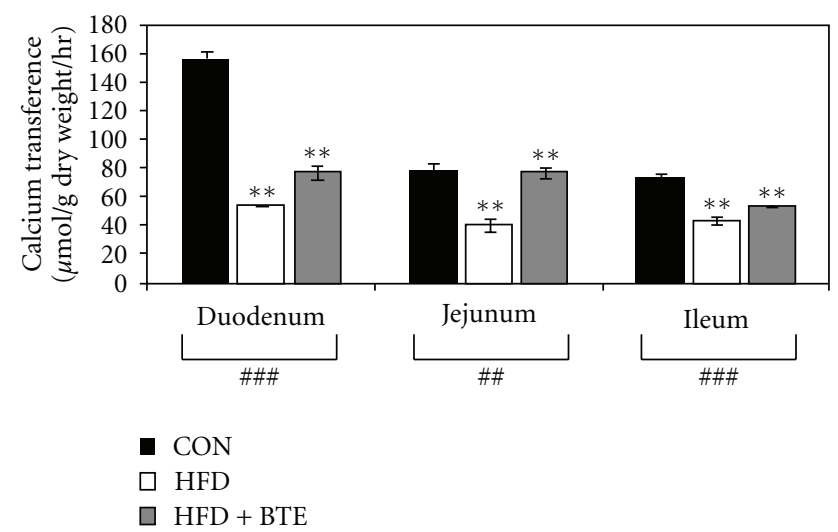

Figure 4: Transference of calcium in duodenal, jejunal, and ileal segments of control (CON; Group A), HFD treated (Group B), and HFD + BTE supplemented (Group C) groups of rats. Values are

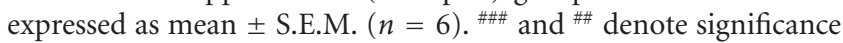
level $P<.001$ and $P<.01$, respectively, based on Kruskal-Wallis nonparametric ANOVA test and ${ }^{* *} P<.01$ denotes significance level based on Mann-Whitney "U" multiple comparison test.

$(P<.01)$. This could be recovered significantly $(P<.01)$ when BTE was supplemented (Group C).

3.7. Serum RANKL and OPG Activity. Figure 3 depicts serum levels of RANKL (Figure 3(a)) and OPG (Figure 3(b)) of different groups of rats. Compared to control, HFD-fed rats showed a decrease in serum OPG $(P<.01)$ level, which was found significantly $(P<.05)$ counter regulated on BTE supplementation. In contrast, compared to control, serum RANKL level was increased significantly $(P<.01)$ in HFDfed animals. On BTE supplementation, a significant decrease $(P<.01)$ in the RANKL level was noted.

3.8. Intestinal Transference of Calcium. Results in Figure 4 depicts that, compared to control, HFD-fed rats (Group B) showed a segment-wise reduction in intestinal transference

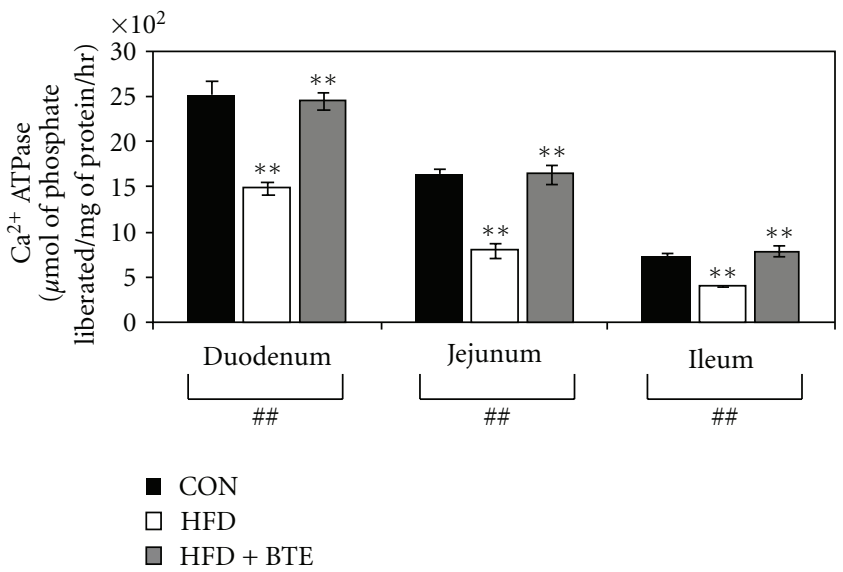

Figure 5: $\mathrm{Ca}^{2+}$-ATPase activity of intestinal mucosal extracts in duodenal, jejunal, and ileal segments of control (CON; Group A), HFD treated (Group B), and HFD + BTE supplemented (Group C) groups of rats. Values are expressed as mean \pm S.E.M. $(n=$ 6). ${ }^{\# P} P<.01$ denotes significance level based on Kruskal-Wallis nonparametric ANOVA test and ${ }^{* *} P<.01$ denotes significance level based on Mann-Whitney "U" multiple comparison test.

of calcium ( $P<.01$ for duodenum, jejunum, and ileum). BTE supplementation could significantly correct such alterations in calcium transference in HFD-fed rats $(P<.01$ for duodenum, jejunum, and ileum).

3.9. Calcium ATPase Activity. Figure 5 shows the effects of feeding of HFD on the mucosal calcium ATPase activity of different segments of small intestine of rats. Results show that, compared to control rats, HFD feeding caused a significant reduction in the activity of this enzyme $(P<.01$ for duodenum, jejunum, and ileum), while BTE supplementation could significantly increase this enzyme activity $(P<$ .01 for duodenum, jejunum, and ileum).

3.10. Intestinal Alkaline Phosphatase Activity. Figure 6 depicts that, compared to control group, HFD-fed rats 


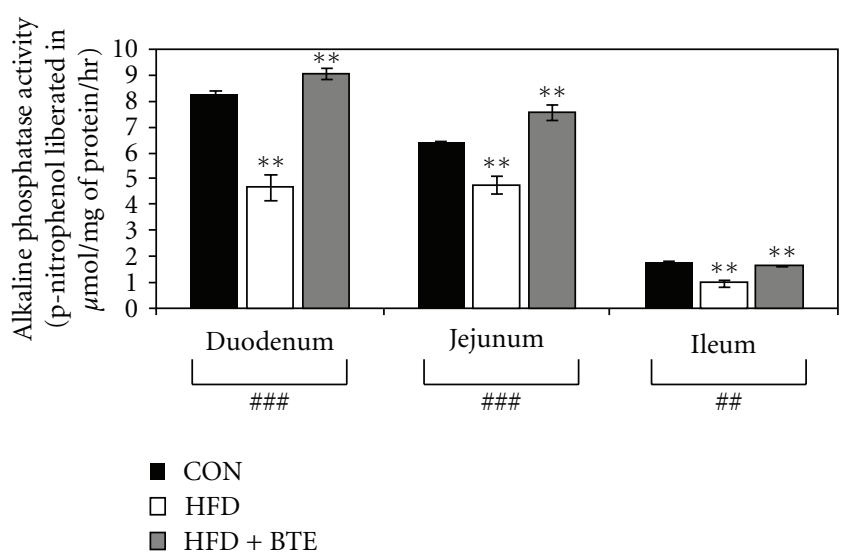

FIGURE 6: Alkaline phosphatase activity of intestinal mucosal extracts in duodenal, jejunal, and ileal segments of control (CON; Group A), HFD treated (Group B), and HFD + BTE supplemented (Group C) groups of rats. Values are expressed as mean \pm S.E.M. $(n=6) .{ }^{\# \#}$ and ${ }^{\# \#}$ denote significance level $P<.001$ and $P<.01$, respectively, based on Kruskal-Wallis nonparametric ANOVA test and ${ }^{* *} P<.01$ denotes significance level based on Mann-Whitney " $U$ " multiple comparison test.

showed a significant reduction in the activity of alkaline phosphatase in all segments of small intestine $(P<.01$ for duodenum, jejunum, and ileum). BTE supplementation was found significantly effective in restoring this enzyme activity in all these segments $(P<.01$ for duodenum, jejunum and ileum).

3.11. Histological Analysis of Cancellous and Cortical Bones. Histological studies of two different types of bones were conducted to determine the in vivo effects of BTE in the HFD-fed animals. HFD-fed rats (Group B) showed a decrease in cortical thickness and empty bone marrow space at the proximal tibia (Figures $7(\mathrm{a})-7(\mathrm{c})$ ) and fourth lumbar vertebra (Figures $7(\mathrm{~d})-7(\mathrm{f})$ ), as compared to control (Group A). Additionally, there was a decrease in trabecular bone volume and thickness at the fourth lumbar vertebra. However, on BTE supplementation, bone repairing actions were seen in these HFD-fed animals.

\section{Discussion}

The present study examined the chemoprotective actions of aqueous black tea extract (BTE) against HFD fed (60\%) NASH skeletal changes. Bone manifestations are well-known as extrahepatic complications of chronic liver disease. Patients with chronic liver disease are at increased risk of developing hepatic osteodystrophy manifested as osteomalacia or osteoporosis [56]. Osteoporosis is a frequent complication of end-stage liver disease irrespective of its etiology [57].

Recent research also suggests that there is a strong positive correlation between osteoporosis and hyperlipidemia. Excess lipid consumption may lead to lipid accumulation and subsequent oxidation within bone vasculature, wherein osteoblastic differentiation may be altered. In addition to their inhibitory role in osteoblastic differentiation, it is believed that because oxidized lipids induce endothelial expression of monocyte chemotactic factors, as well as other potent inducers of osteoclastic differentiation, oxidized lipids may also promote bone resorption [58].

Biochemical markers of bone turnover have been widely used as research tool to measure the effects of drugs on bone remodeling [59]. Elevated levels of bone markers are associated with rapid bone loss and may predict a greater risk of fracture independently of bone mineral density (BMD) variability [10]. In our study, compared to control, HFD treated rats showed an increase in urinary loss of calcium, phosphate, and creatinine (Table 1), which could be significantly corrected by BTE supplementation, suggesting BTE possibly has some positive role in preventing bone resorption and/or increase bone formation or both.

Results of studies of two other specific markers of bone turnover, namely, urinary calcium-to-creatinine $(\mathrm{Ca}: \mathrm{Cr})$ ratio and serum alkaline phosphatase (AP) further support our speculation (Tables 1 and 2, resp.). It was observed that BTE was effective in reducing HFD-induced increase in serum AP and urinary $\mathrm{Ca}: \mathrm{Cr}$ ratio. Since a rise in AP and $\mathrm{Ca}: \mathrm{Cr}$ ratio has been linked with collagen degradation, bone resorption and osteoporosis [60-63], it appeared that BTE was possibly effective in preventing bone loss. A close association of increased serum concentrations of TRAP as a potential index for osteoclastic activity is well established [64]. In the present study, compared to control, HFD-fed animals showed an increase in serum TRAP level (Table 2). However, this response was found well regulated by BTE supplementation, indicating that BTE possibly was effective even in controlling osteoclastic activity to preserve skeletal health.

Such speculations were cross-examined in our studies by measuring parameters like bone density (Table 3 ) and bone mineral content (Table 4). Rats in the HFD fed-group had significantly lower bone densities and mineral content, compared to control rats, which could be significantly regained by BTE supplementation, suggesting again the protective role of BTE against HFD-fed skeletal dysfunctional changes. Further confirmatory evidence in favor of our speculation was obtained in our experiment for bone tensile strength or breaking force, which is required to break the bone. Compared to control, HFD-fed animals showed lower tensile strength (Figure 1), which could be significantly elevated (increase in breaking force) on BTE supplementation.

Chronic liver disease accelerates the development of hypogonadism due to both reduced hypothalamic release of gonadotrophins and primary gonadal failure. A decline in circulating estrogen may be a mediator of bone loss in women and men with chronic liver disease [10]. In the present study, HFD-fed female rats showed a significant decrease in serum estradiol level (Figure 2), which could be considerably restored by BTE supplementation. This result showed that BTE has efficacy as a potent phytoestrogenic compound. The estrogen-enhancing property of flavonoids $[65,66]$ from various extragonadal sites like mesenchymal cells of adipose tissue, osteoblasts, and chondriocytes of bone, numerous sites in the brain, breast, and vasculature 


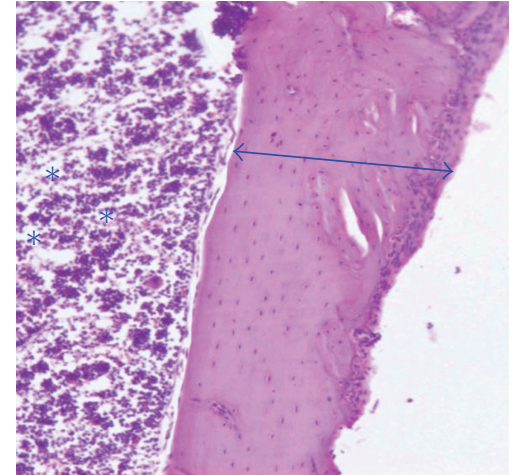

(a)

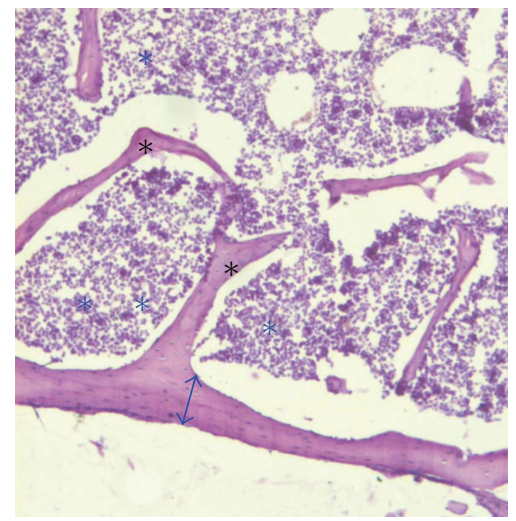

(d)

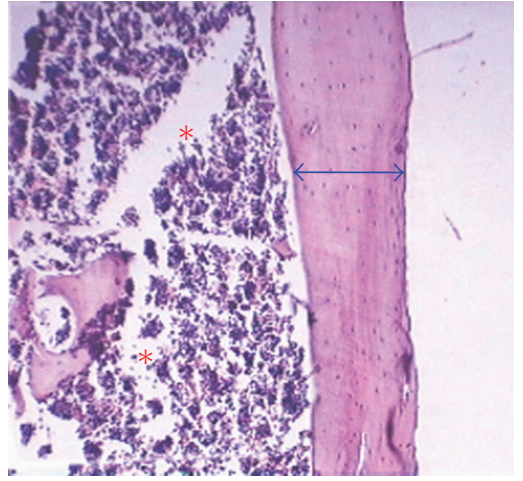

(b)

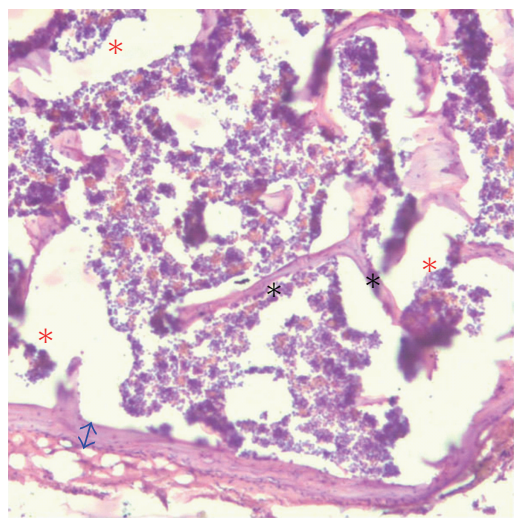

(e)

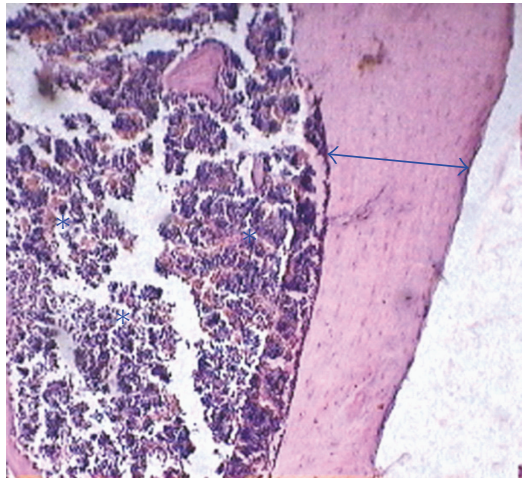

(c)

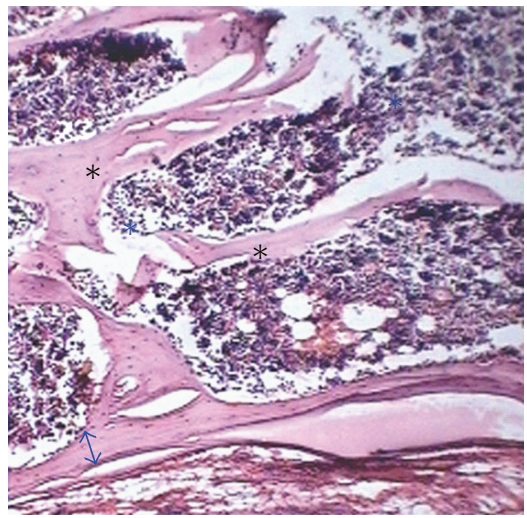

(f)

FIgURE 7: Histological analysis of tibia ((a)-(c)) and lumbar vertebra ((d)-(f)) of rats (hematoxylin-eosin staining, X 100). Representative photomicrograph from HFD group (b) with reduction in cortical thickness and empty bone marrow of the tibia than CON (a) and HFD + BTE (c). Photomicrograph of lumbar vertebra of HFD group (e) with reduction in cortical thickness, empty bone marrow and less trabecular bone compared with CON (d) and HFD + BTE group (f). Blue line, cortical thickness; blue star, bone marrow; red star, empty bone marrow; black star, trabecular thickness.

$[67,68]$ possibly was responsible for such an increase in serum estradiol level by modulating the aromatase activity [68].

Osteoprotegerin (OPG) is a novel receptor that blocks osteoclast formation. Either in a cell membrane-bound or in a soluble form, RANKL, receptor activator of NF-kappa $\beta$ (RANK), stimulates osteoclastogenesis and osteoclastic bone resorption. Factors that stimulate bone resorption increase RANKL expression and, with some exceptions, decrease OPG expression [69]. In the present study, animals of HFD-fed group showed a significant decrease in serum level of OPG (Figure 3(b)) and a significant increase in serum level of RANKL (Figure 3(a)), compared to control group of rats. BTE supplementation, however, could significantly restore altered levels of serum OPG and RANKL, suggesting a more confirmatory protective role of BTE against osteoclastic differentiation and activity in HFD-fed rats.

Calcium absorption has been reported to occur in body throughout the length of the small intestine, the absorption being greater in the duodenum and proximal jejunum than in the ileum [70]. The involvement of two intestinal enzymes, alkaline phosphatase, and $\mathrm{Ca}^{2+}$-ATPase, has been proposed frequently in this phenomenon because the activity of these enzymes correlates with the degree of calcium absorption in different parts of intestinal tract under different circumstances [50, 71, 72]. Results also indicate that $\mathrm{Ca}^{2+}$-induced ATP hydrolysis in the intestine is the result of two enzymatic activities, namely, alkaline phosphatase present in brush border as well as basolateral membranes and a more specific $\mathrm{Ca}^{2+}$-ATPase exclusively located in basolateral plasma membrane [73]. Evidence further indicates that estrogen is more directly involved in determining intestinal calcium absorption because decreased calcium absorption due to ovarian hormone insufficiency is corrected by hormone replacement therapy $[74,75]$. In the present study, intestinal transference of $\mathrm{Ca}^{2+}$ was reduced in HFD-fed rats. Result indicated that deficiency of estrogen had a negative influence upon intestinal transference of calcium, as these animals showed a greater degree of decrease in the transference of calcium than the control animals (Figure 4). Such observation finds its support from earlier findings that estrogen may have direct role via the estrogen receptors in regulating intestinal calcium absorption in vitro and in vivo $[76,77]$. BTE supplementation in the present study was found effective in correcting such reduction in calcium transference, indicating that BTE also possibly had positive influence upon mucosal transference of calcium. 
To ascertain the mechanism of such decrease in intestinal transference of calcium, the activities of two most relevant mucosal calcium transferring enzymes, namely, alkaline phosphatase and calcium-ATPase were examined. Activities of both of these enzymes were found inhibited in HFDfed group of animals (Figures 5 and 6). This supports well the earlier observations that both the enzymes are involved in calcium absorption as the activities of these enzymes correlate with the degree of calcium absorption in different parts of the intestinal tract under different circumstances [50, $71,72]$. BTE supplementation could well restore the activities of both of these enzymes indicating that the observed positive influence of BTE upon intestinal transference of calcium is thus mediated through modulation of activities of these transferring enzymes.

Histological (Figure 7) observation of serial section of tibia and lumbar vertebrae revealed that, compared to control, significant reduction in cortical thickness and bone marrow content was seen in HFD fed rats. On BTE administration, these changes were significantly corrected, suggesting a potential bone repairing action of BTE.

It is recognized that animal studies contain some inherent design limitations. First, restrictions of animal use and therefore sample size; second, the doses required for demonstrating the disease prevention effects are usually higher than the amounts consumed by humans. Furthermore, because of infrastructure limitations it was necessary to rely on biochemical and histological measures rather than using peer reviewed DEXA-derived indices for examining bone profiles. To minimize the error associated with such limitations, we took extreme care while selecting the parameters, collecting data and analyzing them by well-recognized statistical methods followed by us $[34,35]$ earlier.

\section{Conclusions}

In conclusion, results of this study strongly suggest a protective role of BTE against NASH-induced changes in bone metabolism in rats.

\section{Acknowledgment}

The paper was supported by a grant from the National Tea Research Foundation (NTRF), Government of India.

\section{References}

[1] B. Oldenburg and H. Pijli, "Abdominal obesity: metabolic complications and consequences for the liver," Ned Tijdschr Geneeskd, vol. 145, no. 27, pp. 1290-1294, 2001.

[2] A. J. Scheen and F. H. Luyckx, "Obesity and liver disease," Best Practice and Research: Clinical Endocrinology and Metabolism, vol. 16, no. 4, pp. 703-716, 2002.

[3] G. C. Farrell, "Non-alcoholic steatohepatitis: what is it, and why is it important in the Asia-Pacific region?" Journal of Gastroenterology and Hepatology, vol. 18, no. 2, pp. 124-138, 2003.

[4] J. L. Gonzalez-Calvin, F. Gallego-Rojo, R. Fernandez-Perez, F. Casado-Caballero, E. Ruiz-Escolano, and E. G. Olivares,
"Osteoporosis, mineral metabolism, and serum soluble tumor necrosis factor receptor p55 in viral cirrhosis," Journal of Clinical Endocrinology and Metabolism, vol. 89, no. 9, pp. 4325-4330, 2004.

[5] F. J. Gallego-Rojo, J. L. Gonzalez-Calvin, M. Muñoz-Torres, J. L. Mundi, R. Fernandez-Perez, and D. Rodrigo-Moreno, "Bone mineral density, serum insulin-like growth factor I, and bone turnover markers in viral cirrhosis," Hepatology, vol. 28, no. 3, pp. 695-699, 1998.

[6] M. Weinreb, R. D. Pollak, and Z. Ackerman, "Experimental cholestatic liver disease through bile-duct ligation in rats results in skeletal fragility and impaired osteoblastogenesis," Journal of Hepatology, vol. 40, no. 3, pp. 385-390, 2004.

[7] K. Suzuki, J. Takahashi, H. Takada, and H. Kuwayama, "Osteoporosis associated with chronic liver disease," Nippon Rinsho, vol. 62, supplement 2, pp. 728-731, 2004.

[8] P. L. Van Daele and H. A. Pols, "Disorders of bone metabolism in gastrointestinal and hepatic diseases," Ned Tijdschr Geneeskd, vol. 144, no. 10, pp. 462-467, 2000.

[9] O. M. Crosbie, R. Freaney, M. J. McKenna, and J. E. Hegarty, "Bone density, vitamin D status, and disordered bone remodeling in end-stage chronic liver disease," Calcified Tissue International, vol. 64, no. 4, pp. 295-300, 1999.

[10] A. J. Sanchez and A. M. Jaime, "Liver disease and osteoporosis," Nutrition in Clinical Practice, vol. 21, no. 3, pp. 273-278, 2006.

[11] M. Laroche, L. Moulinier, E. Bon, A. Cantagrel, and B. Mazieres, "Renal tubular disorders and arteriopathy of the lower limbs: risk factors for osteoporosis in men?" Osteoporosis International, vol. 4, no. 6, pp. 309-313, 1994.

[12] R. S. Pinals and J. M. Jabbs, "Type-IV hyperlipoproteinaemia and transient osteoporosis," The Lancet, vol. 2, no. 7783, p. 929, 1972.

[13] P. D. Broulik and J. Kapitola, "Interrelations between body weight, cigarette smoking and spine mineral density in osteoporotic Czech women," Endocrine Regulations, vol. 27, no. 2, pp. 57-60, 1993.

[14] K. S. G. Jie, M. L. Bots, C. Vermeer, J. C. M. Witteman, and D. E. Grobbee, "Vitamin K status and bone mass in women with and without aortic atherosclerosis: a population-based study," Calcified Tissue International, vol. 59, no. 5, pp. 352-356, 1996.

[15] E. I. Barengolts, M. Berman, S. C. Kukreja, T. Kouznetsova, C. Lin, and E. V. Chomka, "Osteoporosis and coronary atherosclerosis in asymptomatic postmenopausal women," Calcified Tissue International, vol. 62, no. 3, pp. 209-213, 1998.

[16] Y. Ouchi, M. Akishita, A. C. De Souza, T. Nakamura, and H. Orimo, "Age-related loss of bone mass and aortic/aortic valve calcification reevaluation of recommended dietary allowance of calcium in the elderly," Annals of the New York Academy of Sciences, vol. 676, pp. 297-307, 1993.

[17] F. Parhami, Y. Tintut, W. G. Beamer, N. Gharavi, W. Goodman, and L. L. Demer, "Atherogenic high-fat diet reduces bone mineralization in mice," Journal of Bone and Mineral Research, vol. 16, no. 1, pp. 182-188, 2001.

[18] H. Xu, B. A. Watkins, and M. F. Seifert, "Vitamin E stimulates trabecular bone formation and alters epiphyseal cartilage morphometry," Calcified Tissue International, vol. 57, no. 4, pp. 293-300, 1995.

[19] G. R. Wohi, L. Loehrke, B. A. Watkins, and R. F. Zernicke, "Effects of high-fat diet on mature bone mineral content, structure, and mechanical properties," Calcified Tissue International, vol. 63, no. 1, pp. 74-79, 1998. 
[20] K. K. Krishnamoorthy, "The nutritional and therapeutic value of tea," in Proceedings of the International Symposium on Tea Science, Shizuoka, Japan, 1991.

[21] C. J. Dufresne and E. R. Farnworth, "A review of latest research findings on the health promotion properties of tea," Journal of Nutritional Biochemistry, vol. 12, no. 7, pp. 404-421, 2001.

[22] B. Frei and J. V. Higdon, "Antioxidant activity of tea polyphenols in vivo: evidence from animal studies," Journal of Nutrition, vol. 133, no. 10, pp. 3275S-3284S, 2003.

[23] A. K. Nag Chaudhuri, S. Karmakar, D. Roy, S. Pal, M. Pal, and T. Sen, "Anti-inflammatory activity of Indian black tea (Sikkim variety)," Pharmacological Research, vol. 51, no. 2, pp. 169-175, 2005.

[24] J. A. Vinson and Y. A. Dabbagh, "Effect of green and black tea supplementation on lipids, lipid oxidation and fibrogen in the hamster: mechanism for the epidemiological benefits of tea drinking," The FEBS Letters, vol. 433, pp. 44-46, 1988.

[25] K. Imai and K. Nakachi, "Cross sectional study of effects of drinking green tea on cardiovascular and liver diseases," British Medical Journal, vol. 310, no. 6981, pp. 693-696, 1995.

[26] V. M. Hegarty, H. M. May, and K. T. Khaw, "Tea drinking and bone mineral density in older women," American Journal of Clinical Nutrition, vol. 71, no. 4, pp. 1003-1007, 2000.

[27] C. H. Wu, Y. I. C. Yang, W. J. Yao, F. H. Lu, J. S. Wu, and C. J. Chang, "Epidemiological evidence of increased bone mineral density in habitual tea drinkers," Archives of Internal Medicine, vol. 162, no. 9, pp. 1001-1006, 2002.

[28] Z. Chen, M. B. Pettinger, C. Ritenbaugh et al., "Habitual tea consumption and risk of osteoporosis: a prospective study in the women's health initiative observational cohort," American Journal of Epidemiology, vol. 158, no. 8, pp. 772-781, 2003.

[29] R. J. Miksicek, "Commonly occurring plant flavonoids have estrogenic activity," Molecular Pharmacology, vol. 44, no. 1, pp. 37-43, 1993.

[30] T. Uesugi, Y. Fukui, and Y. Yamori, "Beneficial effects of soybean isoflavone supplementation on bone metabolism and serum lipids in postmenopausal Japanese women: a four-week study," Journal of the American College of Nutrition, vol. 21, no. 2, pp. 97-102, 2002.

[31] M. Mori, T. Aizawa, M. Tokoro, T. Miki, and Y. Yamori, "Soy isoflavone tablets reduce osteoporosis risk factors and obesity in middle-aged Japanese women," Clinical and Experimental Pharmacology \& Physiology, vol. 31, no. 2, pp. S39-S41, 2004.

[32] J. Kanis, O. Johnell, B. Gullberg et al., "Risk factors for hip fracture in men from southern Europe: the MEDOS study. Mediterranean Osteoporosis study," Osteoporosis International, vol. 9, no. 1, pp. 45-54, 1999.

[33] O. Johnell, B. Gullberg, J. A. Kanis et al., "Risk for hip fracture in European women: the MEDOS study. Mediterranean Osteoporosis Study," Journal of Bone and Mineral Research, vol. 10, pp. 1802-1815, 1995.

[34] A. S. Das, M. Mukherjee, D. Das, and C. Mitra, "Protective action of aqueous black tea (Camellia sinensis) extract (BTE) against ovariectomy-induced oxidative stress of mononuclear cells and its associated progression of bone loss," Phytotherapy Research, vol. 23, no. 9, pp. 1287-1294, 2009.

[35] A. S. Das, D. Das, M. Mukherjee, S. Mukherjee, and C. Mitra, "Phytoestrogenic effects of black tea extract (Camellia sinensis) in an oophorectomized rat (Rattus norvegicus) model of osteoporosis," Life Sciences, vol. 77, no. 24, pp. 3049-3057, 2005.

[36] A. S. Das, M. Mukherjee, and C. Mitra, "Evidence for a prospective anti-osteoporosis effect of black tea (Camellia
Sinensis) extract in a bilaterally ovariectomized rat model," Asia Pacific Journal of Clinical Nutrition, vol. 13, no. 2, pp. 210216, 2004.

[37] S. Chanda, M. N. Islam, P. Pramanik, and C. Mitra, "Highlipid diet intake is a possible predisposing factor in the development of hypogonadal osteoporosis," Japanese Journal of Physiology, vol. 46, no. 5, pp. 383-388, 1996.

[38] J. Baumgardner, K. Shankar, T. M. Badger, and M. J. Ronis, "A new rat model for non-alcoholic steatohepatitis," in Proceedings of the 24th Annual Meeting of the South Central Chapter of the Society of Toxicology, p. 18, Little Rock, Ark, USA, 2005.

[39] F. G. Dunlap, P. J. White, and L. M. Pollak, "Fatty acid composition of oil from exotic corn breeding materials," Journal of the American Oil Chemists' Society, vol. 72, no. 9, pp. 989-993, 1995.

[40] H. Wei, X. Zhang, J. F. Zhao, Z. Y. Wang, D. Bickers, and M. Lebwohl, "Scavenging of hydrogen peroxide and inhibition of ultraviolet light-induced oxidative DNA damage by aqueous extracts from green and black teas," Free Radical Biology and Medicine, vol. 26, no. 11-12, pp. 1427-1435, 1999.

[41] R. L. Nath and R. K. Nath, "Techniques in the biochemical investigation of diseases," in Practical Biochemistry in Clinical Medicine, p. 8, Academic Publishers, Calcutta, India, 2nd edition, 1990.

[42] K. O. Adeniyi, O. O. Ogunkeye, and C. O. Isichei, "Thryroidectomy and thyroxine administration alter serum calcium levels in rat," Acta Physiologica Hungarica, vol. 81, no. 1, pp. 95-99, 1993.

[43] H. O. Lowry and A. J. Lopez, "The determination of inorganic phosphate in the presence of labile phosphate esters," The Journal of Biological Chemistry, vol. 162, pp. 421-428, 1946.

[44] R. L. Nath and R. K. Nath, "Tests for renal functioninvestigation of nephrotic syndrome and other primary organ related disorders," in Practical Biochemistry in Clinical Medicine, p. 94, Academic Publishers, Calcutta, India, 2nd edition, 1990.

[45] R. H. Michell, M. J. Karnovsky, and M. L. Karnovsky, "The distributions of some granule-associated enzymes in guineapig polymorphonuclear leucocytes," Biochemical Journal, vol. 116, no. 2, pp. 207-216, 1970.

[46] L. Abbott et al., "Acid phosphatase," in Clinical Chemistry, A. Kaplan et al., Ed., pp. 1079-1083, The C. V. Mosby, St. Louis, Mo, USA, 1984.

[47] B. H. Arjmandi, L. Alekel, B. W. Hollis et al., "Dietary soybean protein prevents bone loss in an ovariectomized rat model of osteoporosis," Journal of Nutrition, vol. 126, no. 1, pp. 161$167,1996$.

[48] R. Shapiro and R. P. Heaney, "Co-dependence of calcium and phosphorus for growth and bone development under conditions of varying deficiency," Bone, vol. 32, no. 5, pp. 532540, 2003.

[49] J. K. Yeh, C. C. Liu, and J. F. Aloia, "Effects of exercise and immobilization on bone formation and resorption in young rats," American Journal of Physiology: Endocrinology and Metabolism, vol. 264, no. 2, pp. E182-E189, 1993.

[50] M. N. Islam, S. Chanda, and C. Mitra, "Effects of different intensities of cold stress on certain physiological phenomena related to skeletal health in a hypogonadal rat model," Journal of physiology and pharmacology, vol. 51, no. 4, pp. 857-870, 2000.

[51] D. D. Maenz and C. I. Cheeseman, "Effect of hyperglycemia on D-glucose transport across the brush-border and basolateral 
membrane of rat small intestine," Biochimica et Biophysica Acta, vol. 860, no. 2, pp. 277-285, 1986.

[52] I. Koyama, K. Tsugikazu, S. Yoshikatsu, and K. Munetsugu, “A possible mechanism for the changes in hepatic and intestinal alkaline phosphatase activities in bile duct ligated rats and guinea pigs," Biochimica et Biophysica Acta, vol. 760, pp. 169$174,1983$.

[53] O. H. Lowry, N. J. Rosenbrough, A. L. Farr, and R. J. Randall, "Protein measurement with the folin phenol reagent," The Journal of Biological Chemistry, vol. 193, no. 1, pp. 265-275, 1951.

[54] G. Rorive and A. Kleinzeller, " $\mathrm{Ca}^{2+}$ activated ATPase from renal tubular cells," Methods in Enzymology, vol. 32, pp. 303306, 1974.

[55] D. Miao and A. Scutt, "Recruitment, augmentation and apoptosis of rat osteoclasts in $1,25-(\mathrm{OH})_{2} \mathrm{D}_{3}$ response to short-term treatment with 1,25-dihydroxyvitamin $\mathrm{D}_{3}$ in vivo," BMC Musculoskeletal Disorders, vol. 3, Article ID 16, pp. 1-10, 2002.

[56] K. A. Mahdy, H. H. Ahmed, F. Mannaa, and A. Abdel-Shaheed, "Clinical benefits of biochemical markers of bone turnover in Egyptian children with chronic liver diseases," World Journal of Gastroenterology, vol. 13, no. 5, pp. 785-790, 2007.

[57] I. Schiefke, A. Fach, M. Wiedmann et al., "Reduced bone mineral density and altered bone turnover markers in patients with non-cirrhotic chronic hepatitis B or C infection," World Journal of Gastroenterology, vol. 11, no. 12, pp. 1843-1847, 2005.

[58] N. Gharavi, "Role of lipids in osteoporotic bone loss," Nutrition Bytes, vol. 8, no. 2, article 2, 2002.

[59] X. X. Xiao, I. Hara, and T. Matsumiya, "Effects of osthole on postmenopausal osteoporosis using ovariectomized rats: comparison to the effects of estradiol," Biological and Pharmaceutical Bulletin, vol. 25, no. 6, pp. 738-742, 2002.

[60] R. Lindsay, J. R. T. Coutts, and D. M. Hart, "The effect of endogenous oestrogen on plasma and urinary calcium and phosphate in oophorectomized women," Clinical Endocrinology, vol. 6, no. 2, pp. 87-93, 1977.

[61] K. H. Myburgh, T. D. Noakes, M. Roodt, and F. S. Hough, "Effect of exercise on the development of osteoporosis in adult rats," Journal of Applied Physiology, vol. 66, no. 1, pp. 14-19, 1989.

[62] P. D. Delmas, "Biochemical markers of bone turnover," Journal of Bone and Mineral Research, vol. 8, no. 2, pp. S549-S555, 1993.

[63] B. J. Gertz, P. Shao, D. A. Hanson et al., "Monitoring bone resorption in early postmenopausal women by an immunoassay for cross-linked collagen peptides in urine," Journal of Bone and Mineral Research, vol. 9, no. 2, pp. 135142, 1994.

[64] J. J. Stepan, "Enzyme tests in bone disease," in Enzyme Tests in Diagnosis, D. W. Moss and S. B. Rosalki, Eds., pp. 155-188, Oxford University Press, New York, NY, USA, 1996.

[65] Y. N. Jiang, H. Y. Mo, and J. M. Chen, "Effects of epimedium total flavonoids phytosomes on preventing and treating boneloss of ovariectomized rats," Zhongguo Zhong yao Zazhi, vol. 27, no. 3, pp. 221-224, 2002.

[66] B. Li and S. Yu, "Genistein prevents bone resorption diseases by inhibiting bone resorption and stimulating bone formation," Biological and Pharmaceutical Bulletin, vol. 26, no. 6, pp. 780-786, 2003.

[67] E. R. Simpson and S. R. Davis, "Minireview: aromatase and the regulation of estrogen biosynthesis: some new perspectives," Endocrinology, vol. 142, no. 11, pp. 4589-4594, 2001.
[68] E. R. Simpson, C. Clyne, C. Speed, G. Rubin, and S. Bulun, "Tissue-specific estrogen biosynthesis and metabolism," Annals of the New York Academy of Sciences, vol. 949, pp. 5867, 2001.

[69] H. Chung, Y. S. Kang, C. S. Hwang et al., "Deflazacort increases osteoclast formation in mouse bone marrow culture and the ratio of RANKL/OPG mRNA expression in marrow stromal cells," Journal of Korean Medical Science, vol. 16, no. 6, pp. 769-773, 2001.

[70] M. R. Wills, "Intestinal absorption of calcium," The Lancet, vol. 1 , no. 7807, pp. 820-822, 1973.

[71] C. Gennari, B. Imbimbo, M. Montagnani, M. Bernini, P. Nardi, and L. V. Avioli, "Effects of prednisole and deflazacort on mineral metabolism and parathyroid hormone activity in humans," Calcified Tissue International, vol. 36, pp. 245-252, 1984.

[72] S. Chanda, N. Islam, T. K. Ghosh, and C. Mitra, "Effects of a high intake of unsaturated and saturated oils on intestinal transference of calcium and calcium mobilization from bone in an ovariectomized rat model of osteoporosis," Asia Pacific Journal of Clinical Nutrition, vol. 8, no. 2, pp. 115-120, 1999.

[73] W. E. J. M. Ghijsen, M. D. DeJong, and C. H. Van Os, "Association between $\mathrm{Ca}^{2+}$ ATPase and alkaline phosphatase activities in plasma membranes of rat duodenum," Biochimica et Biophysica Acta, vol. 599, pp. 538-551, 1980.

[74] M. T. Bolscher, J. C. Netelenbos, R. Barto, L. M. Van Buuren, and W. J. F. Van Der Vijgh, "Estrogen regulation of intestinal calcium absorption in the intact and ovariectomized adult rat," Journal of Bone and Mineral Research, vol. 14, no. 7, pp. 1197-1202, 1999.

[75] A. A. Cotter, C. Jewell, and K. D. Cashman, "The effect of oestrogen and dietary phyto-oestrogens on transepithelial calcium transport in human intestinal-like Caco-2 cells," British Journal of Nutrition, vol. 89, no. 6, pp. 755-765, 2003.

[76] B. H. Arjmandi, B. W. Hollis, and D. N. Kalu, "In vivo effect of $17 \beta$-estradiol on intestinal calcium absorption in rats," Bone and Mineral, vol. 26, no. 2, pp. 181-189, 1994.

[77] M. A. Salih, S. H. Sims, and D. N. Kalu, "Putative intestinal estrogen receptor: evidence for regional differences," Molecular and Cellular Endocrinology, vol. 121, no. 1, pp. 47-55, 1996. 


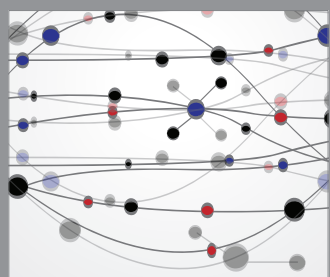

The Scientific World Journal
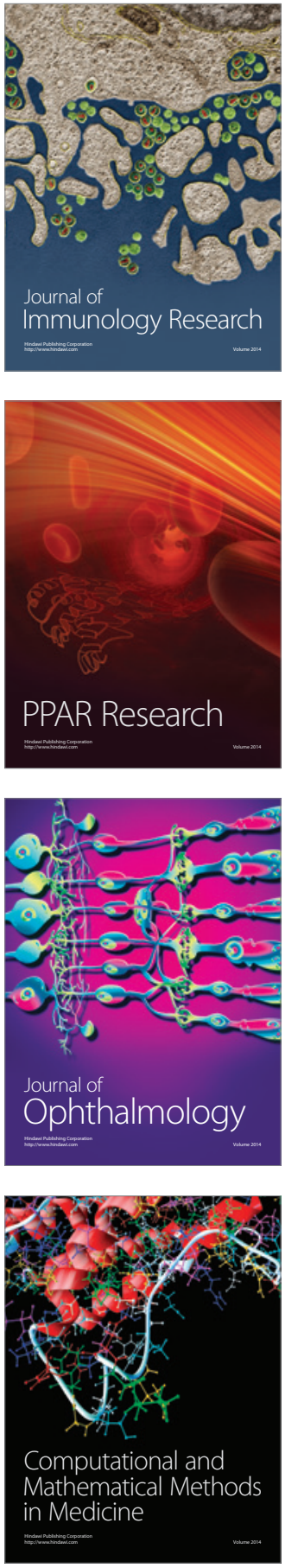

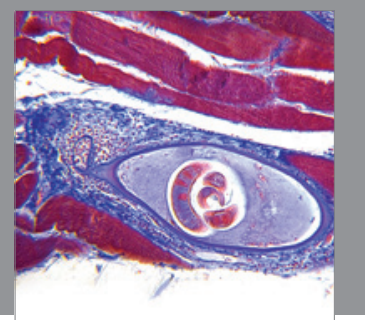

Gastroenterology

Research and Practice
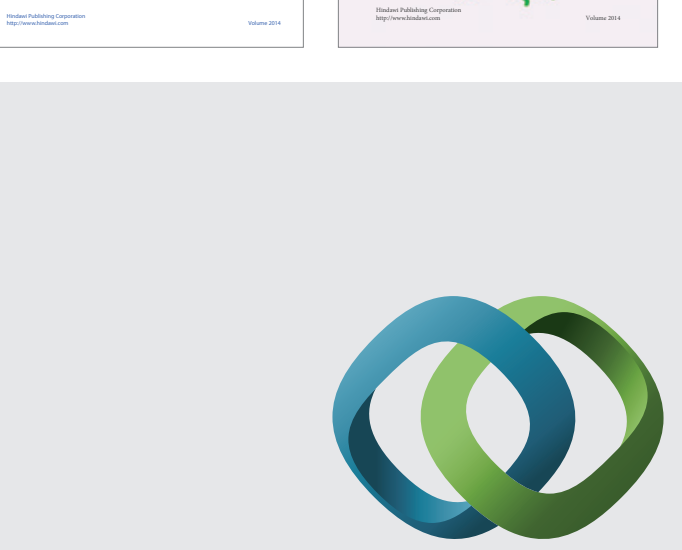

\section{Hindawi}

Submit your manuscripts at

http://www.hindawi.com
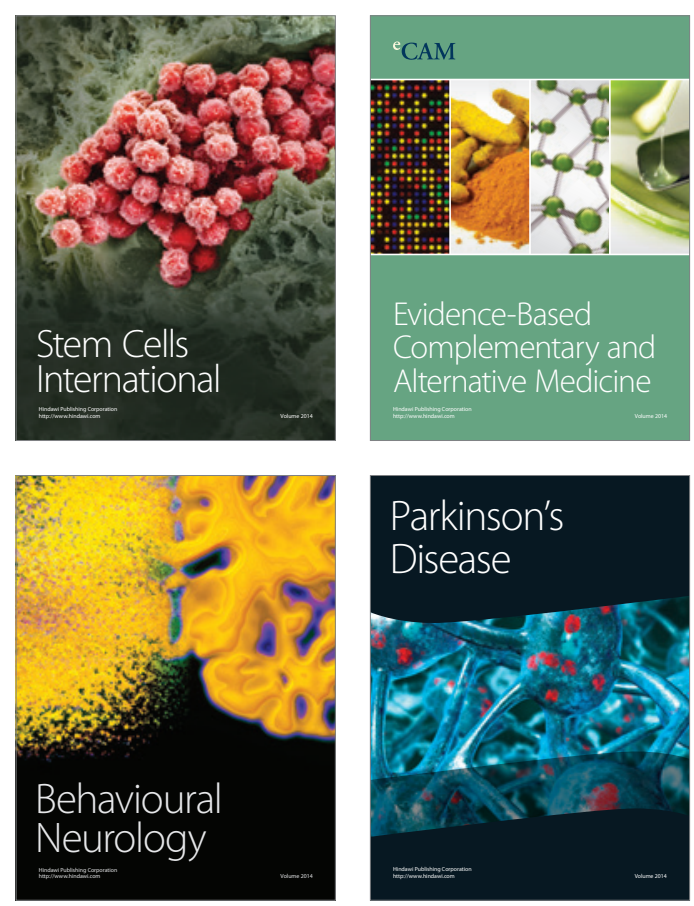

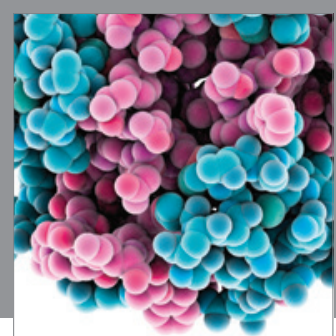

Journal of
Diabetes Research

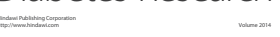

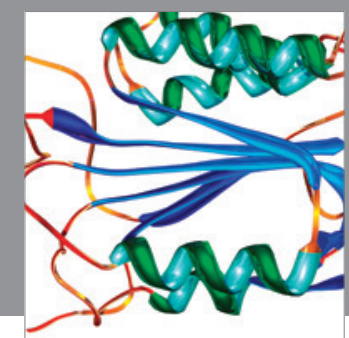

Disease Markers
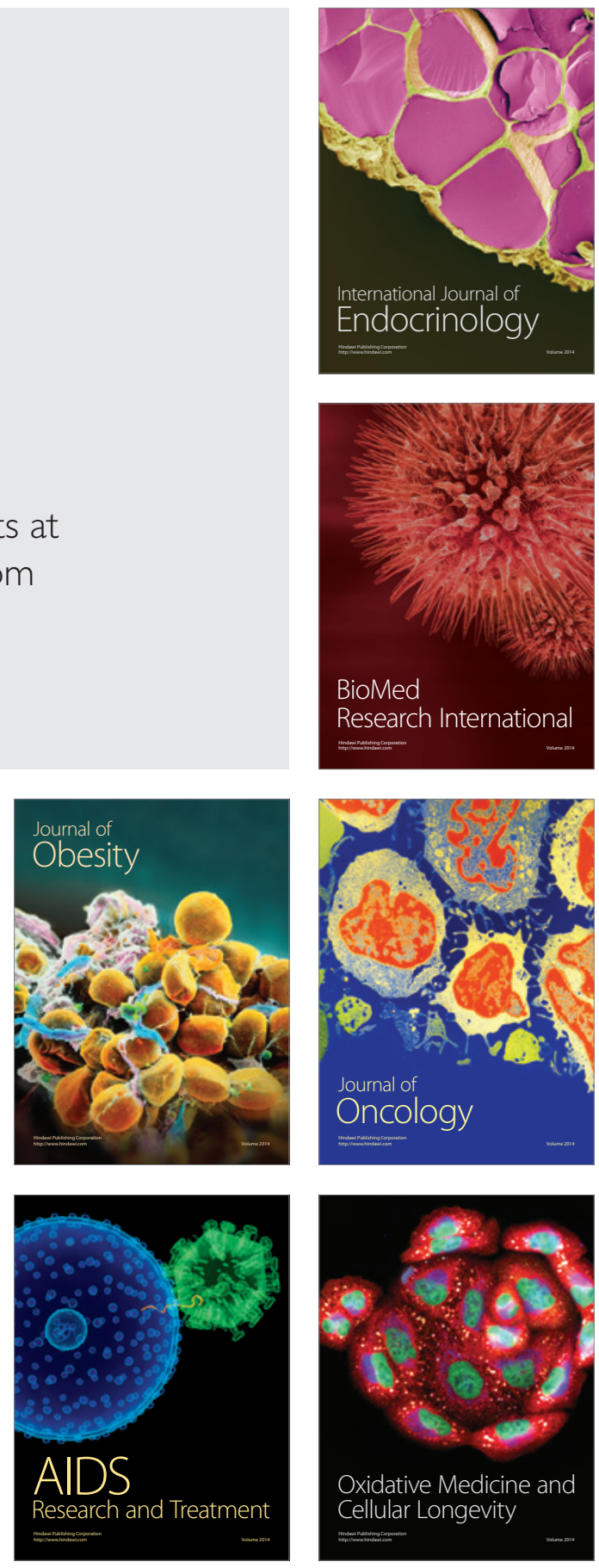